\title{
LA-UR- $97-891$
}

CONF-970944--1

Approved for public release; distribution is unilimited.

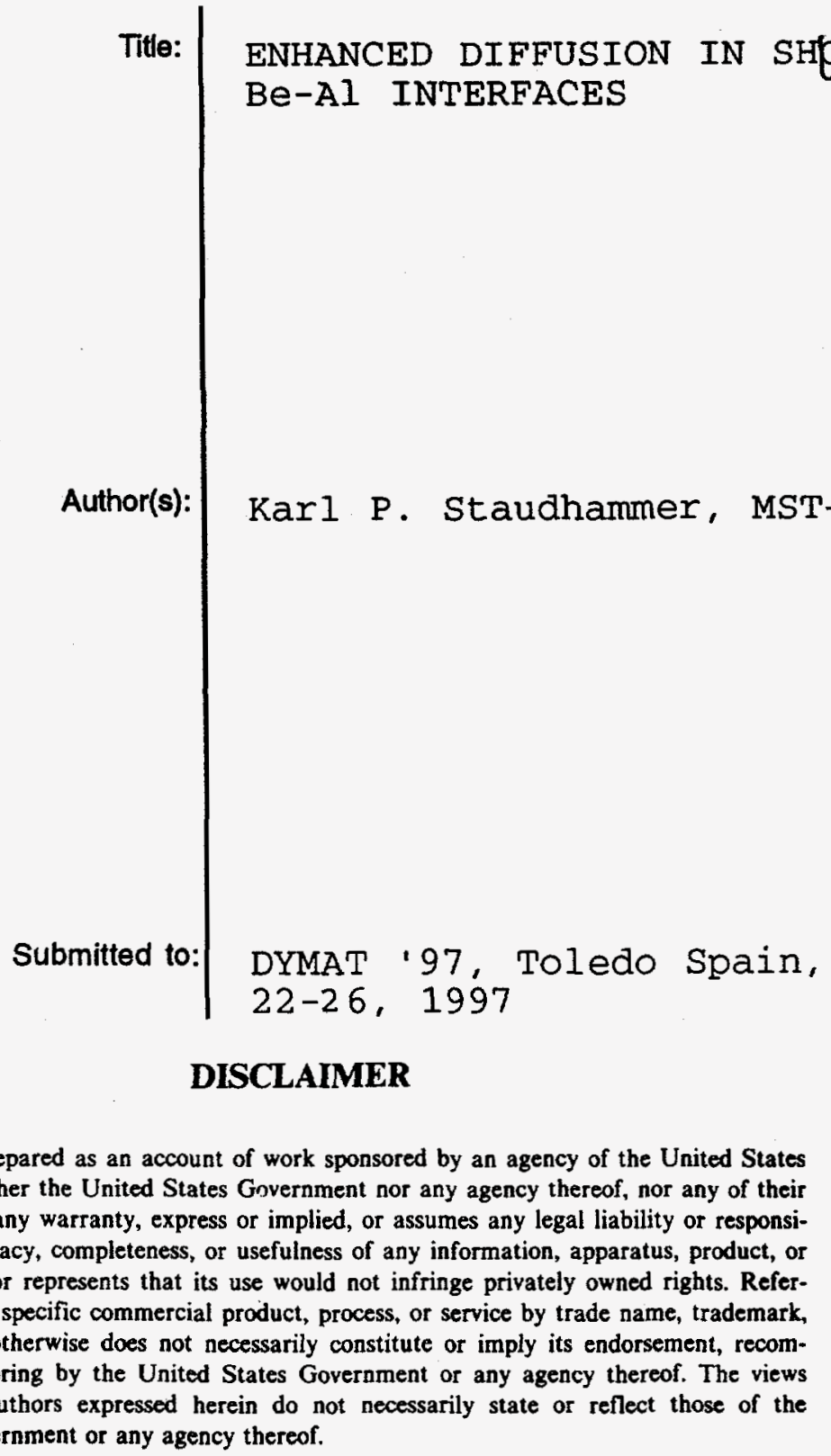

This report was prepared as an account of work sponsored by an agency of the United States Government. Neither the United States Government nor any agency thereof, nor any of their employees, makes any warranty, express or implied, or assumes any legal liability or responsibility for the accuracy, completeness, or usefulness of any information, apparatus, product, or process disclosed, or represents that its use would not infringe privately owned rights. Reference herein to any specific commercial product, process, or service by trade name, trademark, manufacturer, or otherwise does not necessarily constitute or imply its endorsement, recommendation, or favoring by the United States Government or any agency thereof. The views and opinions of authors expressed herein do not necessarily state or reflect those of the United States Government or any agency thereof.

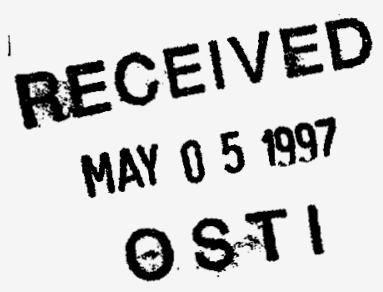

\section{Los Alamos}

NATIONAL LABORATORY

\section{MASTER}

Los Alarnos National Laboratory, an attirmative actionequal opportunity employer, is operated by the University of California lor the U.S. Department of Energy under contract W-7405-ENG-36. By acceptance of this article, the publisher recognizes that the U.S. Government retains a nonexclusive, royalty-free license to publish or reproduce the published form of this contribution, or to allow others to do so, lor U.S. Government purposes. Los Alamos National Laboratory requests that the publisher identify this article as work performed under the ausplces of the U.S. Department of Energy. The Los Alamos National Laboratory strongiy supports academic freedom and a researcher's right to publish; as an institution, however, the Laboratory does not endorse the viewpoint of a publication of guarantee its technical correctness. 


\section{DISCLAmIER}

Portions of this document may be illegible in electronic image products. Images are produced from the best available original docomerot. 


\title{
ENHANCED DIFFUSION IN SHOCK ACTIVATED Be-AI INTERFACES
}

\author{
K. P. Staudhammer \\ Los Alamos National Laboratory, Materials Science \& Technology Division, P.O. Box 1663, \\ Los Alamos, NM 87545
}

\begin{abstract}
Enhanced diffusion of aluminum in shock activated beryllium has been observed. Cylindrical samples of aluminum coated beryllium rods were axisymetrically loaded up to $40 \mathrm{GPa}$ and a total residual strain of up to $6.7 \%$. The defect microstructure produced by both the shock wave and strain enabled the transport of aluminum in beryllium to exceed its equilibrium solid state saturation. This "super saturated" aluminum, upon heating exsolves out at relatively low temperatures and forms very strong interfaces with pressure mated components.
\end{abstract}

\section{INTRODUCTION}

The major driving force for this work was to improve/enhance fabrication of beryllium components that are diffusion bonded. The use of diffusion bonding for components that can not be welded or brazed, can be enhanced by shock activation. The obvious advantage of diffusion bonding is its potential for lower thermal treatments in component fabrication. Normal diffusion is time-temperature and microstructure dependent and the ultimate solubility will be characteristic of the system being considered. Therefore, desirable enhancement for diffusion bonding would be to reduce either temperature or time or both for the required process. Additionally, if solubility can significantly be increased, higher strengths of the bond could be expected. Earlier high static pressure work on the Al-Si equilibrium phase diagram [1] has shown that pressures up to $50 \mathrm{~Kb}$ have a dramatic effect on the solubility of Si on Al from $\sim 1$ at. \% $(1 \mathrm{~atm}$.) to 7 at. \% $(50 \mathrm{~Kb})$. Also an increase of the eutectic temperature from $577^{\circ} \mathrm{C}\left(1 \mathrm{~atm}\right.$.) to $677^{\circ} \mathrm{C}(50 \mathrm{~Kb})$, As well as almost tripling the eutectic point reaction from 12.1 at. \% $(1 \mathrm{~atm}$.) to 29 at. $\%(50 \mathrm{~Kb})$. This is shown in Fig. 1. Based on these results it was decided to pursue similar such effects in Be. Traditionally $\mathrm{Al}$ and $\mathrm{Al}$ alloys have been used as a "braze" material because of its much lower melting temperature relative to beryllium. Aluminum is but one of only two simple eutectic systems with $\mathrm{Be}$ and is shown in Fig. 2 [2], the other one being silicon. Silicon was not considered because of its relatively high eutectic temperature and its brittle nature. Additionally, silicon has a very low solubility in beryllium.

Defects in crystal structures can generally enhance diffusion of second element constituents, particularly if the homologous temperature of the second element is much lower than the matrix which contains the atomic defects. This is an ideal situation for the Al-Be system in that Al has its melting point at 0.60 of that for Be. Thus, if the Be were defected by shock loading, these defects would not appreciably be annealed out at the temperatures used for the diffusion of the aluminum. Consequently, the hope that $\mathrm{Al}$ would have enhanced diffusion in microstructurally defected $\mathrm{Be}$. Thus shock loading concomitant with controlled strains of intement contact $\mathrm{Al} / \mathrm{Be}$ interfaces were performed to measure this effect.

\section{EXPERIMENTAL METHODS}

Beryllium rods having a nominal purity of $99.9 \%$ and of $3.0 \mathrm{~mm}$ in diameter and $6.7 \mathrm{~cm}$ in length were vacuum vapor deposited with $\mathrm{Al}$ (nominal purity of $99.99 \%$ ) on its outer circumference to a thickness of approximately $10 \mu \mathrm{m}$. This rod was then inserted into a $1100 \mathrm{Al}$ sleeve having a $9.5 \mathrm{~mm}$ outside diameter which in turn was inserted into a 304 stainless steel holder assembly having a $3.8 \mathrm{~cm}$ outside diameter and is illustrated in Fig. 3. The holder assembly was then incorporated into a axisymetric shock assembly as shown in Fig. 4. The actual strain rate, which can be deduced from the hydrocode plots were in the range of $10^{6} / \mathrm{s}$ and the shock pulse duration's were calculated to be less than $1 \mu$ s and have been described earlier [3-5]. The shock and the associated controlled strains are shown in Fig. 5a, b for two separate samples investigated. The shock pressures were obtained from a $2 \mathrm{D}$ eularian hydrocode and the strains were measured 


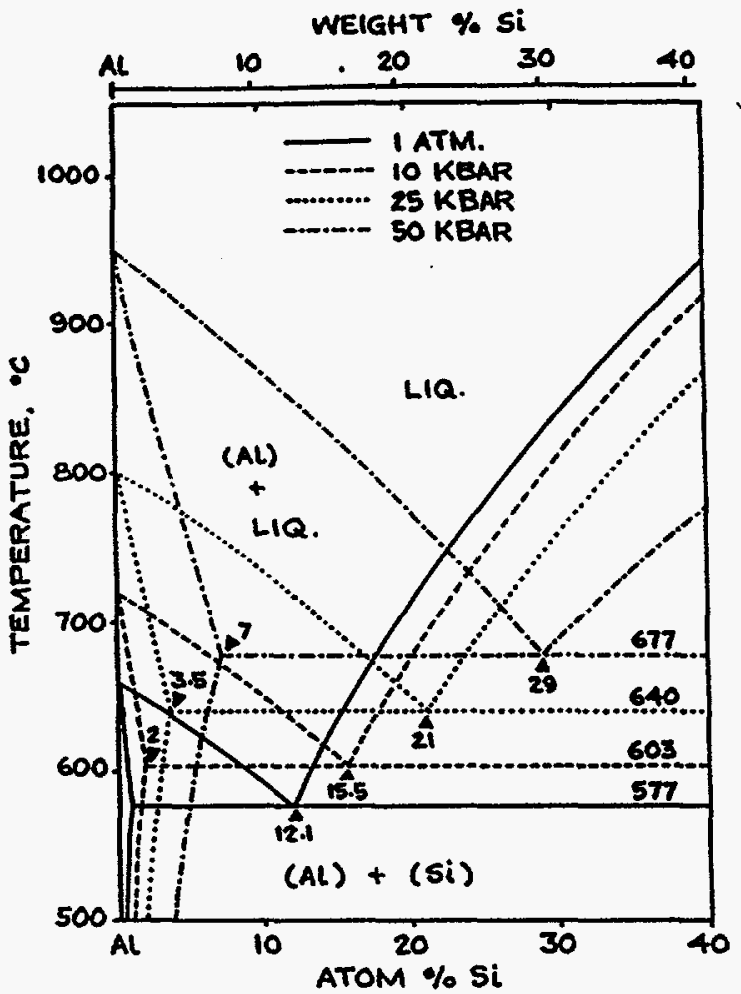

Fig. 1 Influence of high pressure on the Al-Si composition diagram, after [1].

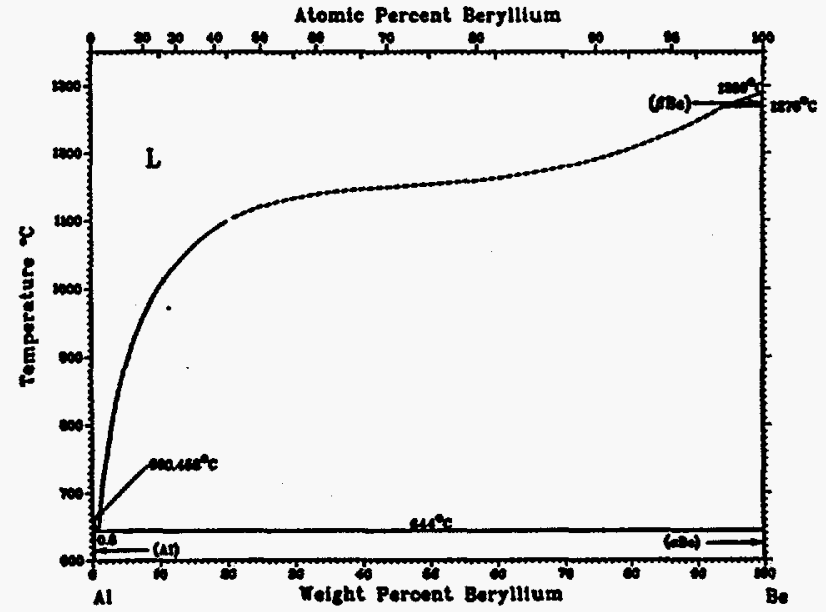

Fig. 2 The Al-Be equilibrium diagram, after [2].
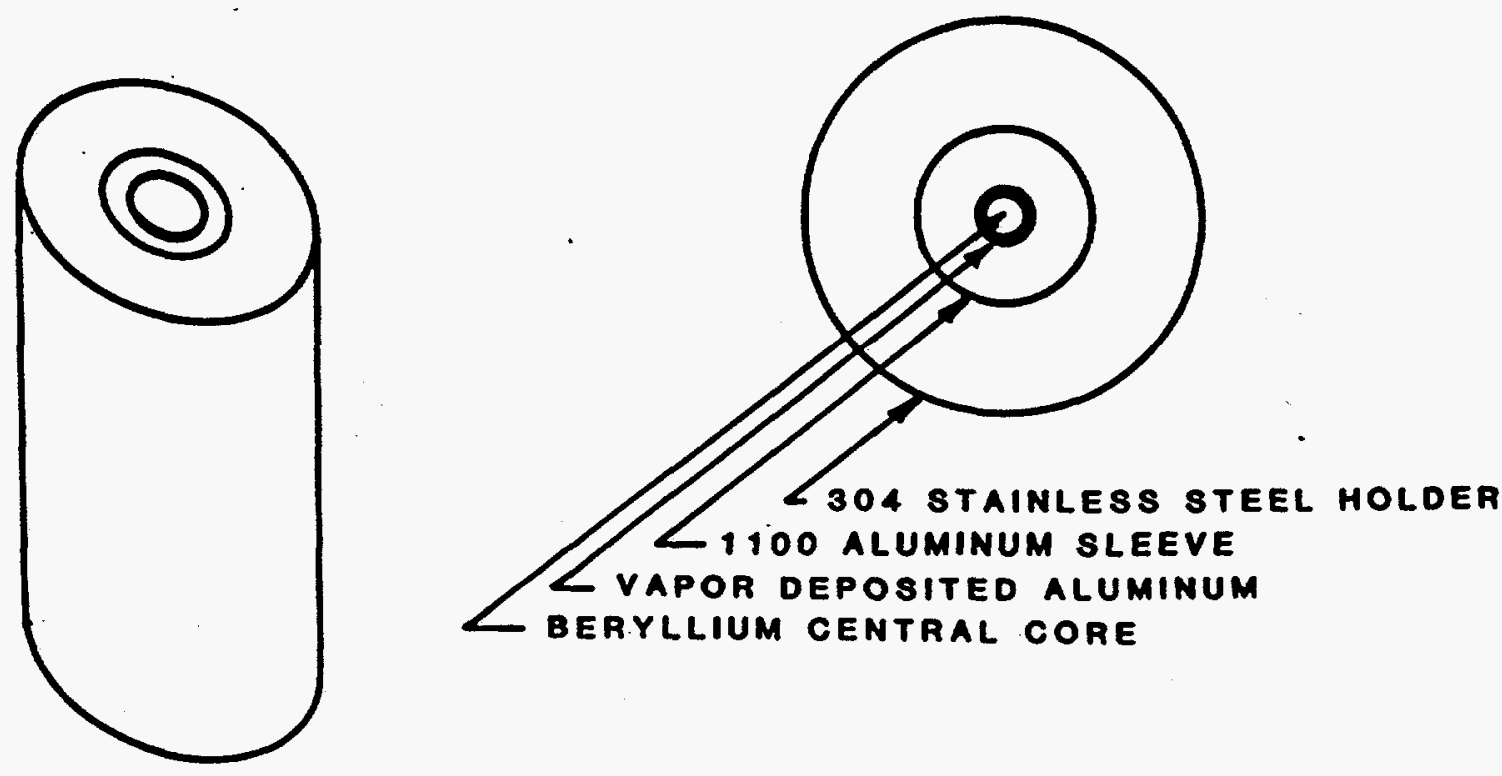

Fig. 3 Schematic of the shock holder assembly used for the Al-Be experiment. 
using photo printed circle grids on the $1100 \mathrm{Al}$ sleeve. The circle griding technique is described elsewhere [5-8]. Samples were then cut from the post shocked rods at specific positions along its length. Each sample is listed with their associated pressures and strains, these values were obtained as described above and are illustrated in Fig. 5. These parameters are given in table I. In these experiments the shock pressures ranged from 4 to $40 \mathrm{GPa}$ in the Be with a concomitant strain of approximately 0 to $6.7 \%$ at the high pressure end for the first sample and $0-3.4 \%$ for the other having the same pressure range. After shock loading, the samples were extracted and characterized as to the amount of $\mathrm{Al}$ transported across the interface and into the $\mathrm{Be}$ rod. The amount of $\mathrm{Al}$ in $\mathrm{Be}$ (and $\mathrm{Be}$ in $\mathrm{Al}$ ) was measured by Energy Dispersive Analysis (EDX) and wavelength spectroscopy. To study the exsolution profiles of the $\mathrm{Al}$, heat treat temperatures used in this investigation on post shocked samples were $645^{\circ} \mathrm{C}$ (solid state) for all the samples as well as $680^{\circ} \mathrm{C}$ (melt) on the highest strain portion (most defected) of the Be samples. These were also characterized by EDX and wave length spectroscopy.

\section{RESULTS AND DISCUSSIONS}

Characterization of the $\mathrm{Al}$ and $\mathrm{Be}$ were made on the eight samples listed in Table I. Beryllium transport into Al was not detected in any of the shocked samples. However, Al transport was detected to varying concentrations at and near the Be interface and are also listed in Table I. Using the data of Table I, a plot of the effect of strain at essentially constant shock pressure as a function of $\mathrm{Al}$ transported into the Be at the interface is shown in Fig. 6. Evident from this plot is the obvious effect of both pressure and strain. Even the effect of low shock pressure and low strain produced more than a 15 fold increase in $\mathrm{Al}$ concentration. While the intermediate shock pressure, though somewhat higher strains, essentially doubles the Al concentration over that of the low pressure and low strain. The effect of high shock pressure has a dramatic effect over that of the low and intermediate shock pressure, even at similar strains (sample 8, at 3.4\% strain). The Al concentrations increased more than five fold over that of the low pressure and low strain.

However, roughly doubling the strain to $6.5 \%$, at $40 \mathrm{GPa}$, the Al concentration increases to 0.6 wt. \%. This in essence is about a 100 fold increase over the room temperature equilibrium concentration. One must keep in mind that while this is a phenomenal increase, it only occurs within the first few microns of the outer diameter of the Be rod.

Solid state heat treatment was under taken to observe the diffusion of $\mathrm{Al}$. The concentration gradient of $\mathrm{Al}$ across the $\mathrm{Al} / \mathrm{Be}$ interface into the $\mathrm{Be}$ rod is shown in Fig. 7 Evident from this figure is a general increase in $\mathrm{Al}$ concentration above the as shocked values when heat treated at $645^{\circ} \mathrm{C}$ for $1 \mathrm{hr}$. Not only has the $\mathrm{Al}$ increased at the measured distance from the interface, it has diffused further into the Be rod in concentrations well above that for equilibrium, up to a depth of 8 $\mu \mathrm{m}$. Further past the interface and into the $\mathrm{Be}(8-16 \mu \mathrm{m})$ the Al concentration approaches that of the equilibrium saturation at $645^{\circ} \mathrm{C}$. A possible explanation for the Al concentration increases after heat treatment can be explained as a result of the increased defected microstructure resulting from a combination of both the shock pressure and associated strain of the Be. This would enhance lower energy diffusion paths that remain available for the $\mathrm{Al}$ for quite some time as the heat treatment temperature is only 0.59 of the melt temperature of the Be. Fig. 8 shows the results of this $\mathrm{Al}$ exsolution from samples 4 and $4 \mathrm{a}$. Sample 4 had undergone a $40 \mathrm{GPa}$ shock pressure and a concomitant strain of $6.5 \%$, its $\mathrm{Al}$ concentration started out with $0.6 \mathrm{wt}$. \% Al at the interface, and after heat treatment at $645^{\circ} \mathrm{C}$ for $1 \mathrm{hr}$., increased to $0.8 \mathrm{wt}$. \% Al. However, at a depth of $10 \mu \mathrm{m}$ from the $\mathrm{Al} / \mathrm{Be}$ interface the $0.05 \mathrm{wt}$. \% Al concentration when annealed further, continued to decrease, moving closer to that of the equilibrium concentration of $\sim 0.008 \mathrm{wt}$. \%. When the sample was heated to $680^{\circ} \mathrm{C}$ (Al melt) for $15 \mathrm{~min}$., the $0.05 \mathrm{wt}$. \% Al concentration at a depth of $10 \mu \mathrm{m}$ decreased to $0.01-0.018 \mathrm{wt}$. \% Al. The resultant solubility of the melted sample is much less but still more than equilibrium saturation of $\mathrm{Al}$ in $\mathrm{Be}$. The lower solubility is attributed to the natural exsolution of the $\mathrm{Al}$ from the $\mathrm{Be}$ via the higher driving force (higher temperature) towards 


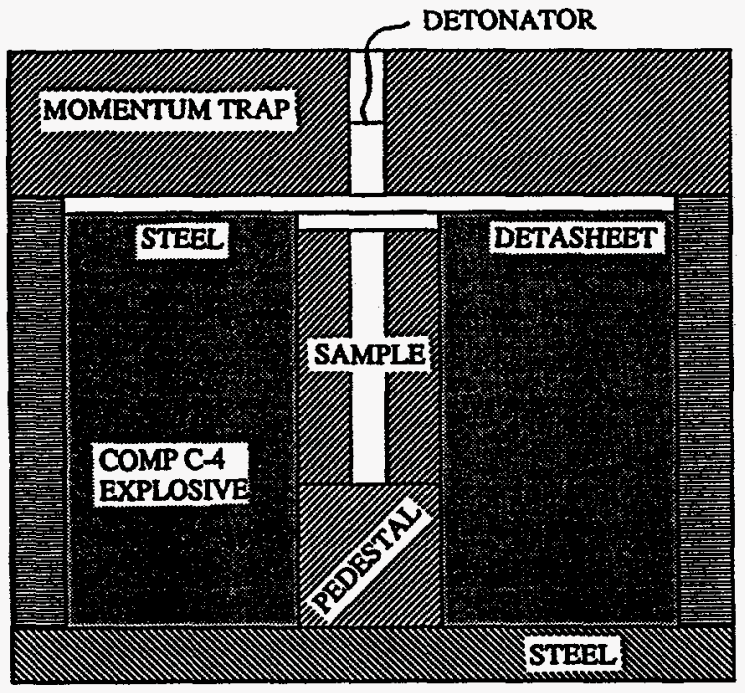

Fig. 4 Schematic of the explosive shock loading assembly.
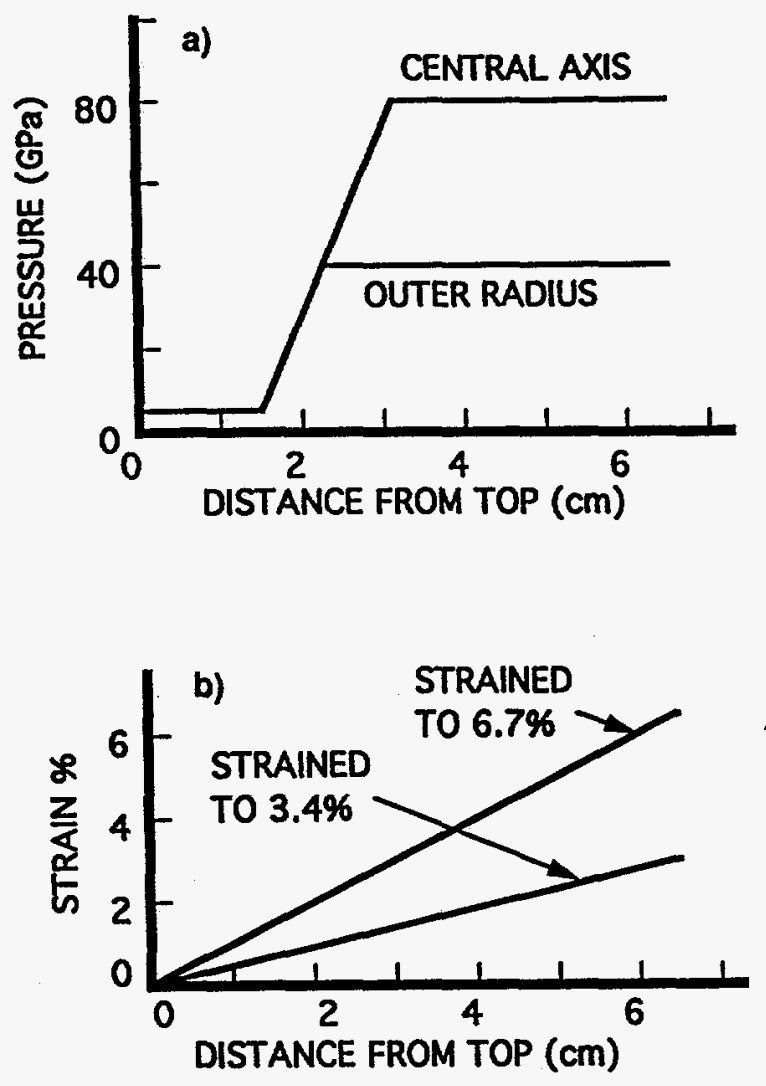

Fig. 5 a) Hydrocode pressure profile of the beryllium, b) Associated shock strain experienced by the $\mathrm{Be}$.

TABLE I. Amount of Aluminum in Beryllium before and after heat treatment for shock and strain conditions listed.

\begin{tabular}{|c|c|c|c|c|c|}
\cline { 4 - 6 } & \multicolumn{3}{c|}{} & \multicolumn{4}{c|}{ At the Interface in Be } \\
\hline Sample & $\begin{array}{c}\text { Shock } \\
\text { Pressure } \\
\mathrm{GPa}\end{array}$ & $\begin{array}{c}\text { Strain } \\
\%\end{array}$ & $\begin{array}{c}\text { wt.\% Al in } \\
\text { Be (post } \\
\text { shocked) }\end{array}$ & $\begin{array}{c}\text { wt.\% Al in Be } \\
\text { after 1 hr. at } \\
645^{\circ} \mathrm{C}\end{array}$ & $\begin{array}{c}\text { wt. \% Al in Be } \\
\text { after 15 min. at } \\
680^{\circ} \mathrm{C}\end{array}$ \\
\hline 1 & 4 & $\sim 1$ & .05 & .01 & \\
\hline 2 & 34 & 2.4 & .15 & .017 & \\
\hline 3 & 40 & 3.4 & .25 & .032 & \\
\hline 4 & 40 & 6.5 & .6 & .8 & $.01-.015$ \\
\hline $4 a$ & 40 & 6.7 & .6 & - & \\
\hline 5 & 4 & 0.6 & .03 & .01 & \\
\hline 6 & 30 & 2.1 & .11 & .013 & \\
\hline 7 & 32 & 2.6 & .18 & .028 & \\
\hline 8 & 40 & 3.4 & .20 & .066 & \\
\hline
\end{tabular}


equilibrium. Consequently, this high non-equilibrium solubility of $\mathrm{Al}$ in $\mathrm{Be}$ is indeed the driving force necessary to promote lower temperature-time diffusion bonding.

To test the diffusion enhancement of these shocked and strained samples, a few samples from the rods were machined down then ground and fine sanded down to their Be diameters. They were then reinserted into an $1100 \mathrm{Al}$ disk and then heat treated as before $\left(645^{\circ} \mathrm{C}\right.$ for $1 \mathrm{hr}$.). The resulting diffusion bond passed the normal punch test which showed that the interface was intact and had shear failed in the $1100 \mathrm{Al}$.

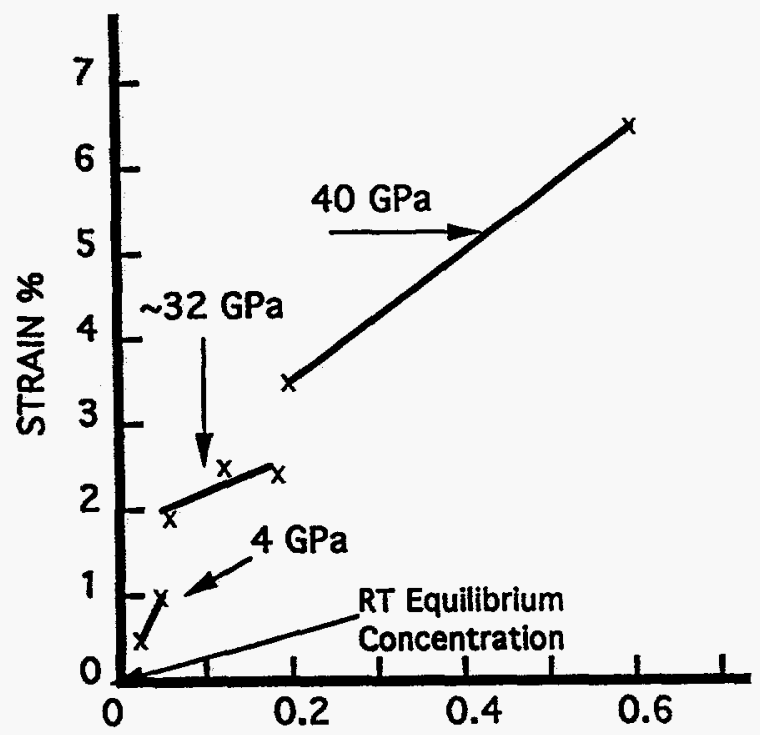

Wt. \% AI IN Be AT INTERFACE

Fig. 6 Effect of strain as a function of aluminum transport into beryllium at the interface for essentially constant post shock pressures.

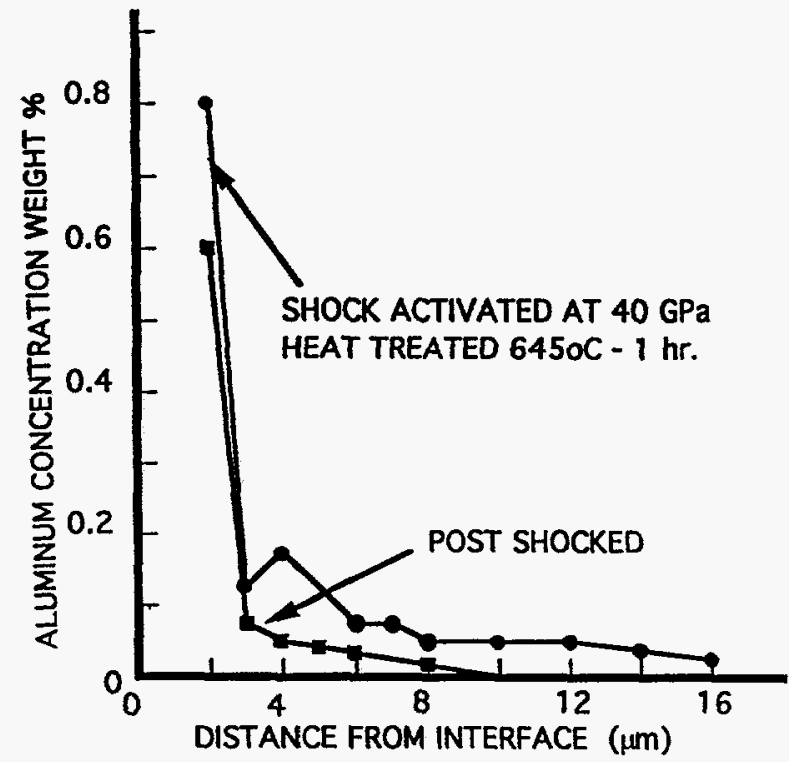

Fig. 7 Concentration gradient of aluminum across the $\mathrm{Al} / \mathrm{Be}$ interface.

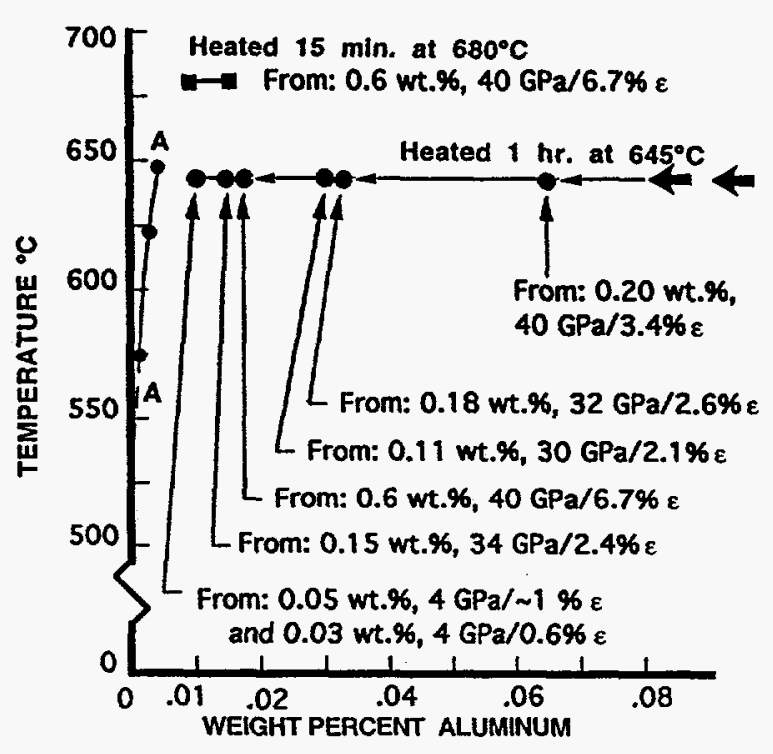

Fig. 8 Solubility's in the Al/Be system. A-A is the equilibrium saturation of $\mathrm{Al}$ in $\mathrm{Be}$. 


\section{CONCLUSIONS}

The present investigation was concerned with enhancing diffusion of $\mathrm{Al}$ in shock activated $\mathrm{Be}$. Shock/strain activation of Be did significantly enhance Al mass transport. Which upon thermal treatment enhances thermal diffusion, thus allowing for the use of lower temperatures or shorter times at higher temperatures. There is a strong correlation between pressure/strain and Al transport into the near surface of the $\mathrm{Be}$ in post shocked material. The amount of transported $\mathrm{Al}$ was greatest for the highest pressures and strains. The Be/Al post shocked and strained samples, bonded under thermal treatments for all shock conditions tested. While only a few punch tests were carried out on the highest pressure/strained samples the diffusion bonded interfaces were stronger than the $1100 \mathrm{Al}$.

\section{REFERENCE:}

1. D. B. Chernov and A. Ya. Schinyaev in Struktura Faz, azovye Prevrashcheniya I Diagrammi Sostoyaniya Metallicheskikh Sistem. "Nauka", 1974, pp. 80-84.

2. Binary Alloy Phase Diagrams, Vol. 1 ed. T. B. Massalski, ASM International Pub., Metals Park, Ohio, 1990, p. 127.

3. K. P. Staudhammer, K. A. Johnson, and B. W. Olinger, Third APS Topical Conf. Shock Waves in Condensed Matter-1983, Elsevier Science Publishers B. V., 1984, pp. 419-24.

4. K. P. Staudhammer and K. A. Johnson, in High-Strain-Rate $-106 / \mathrm{s}$ Response of 304 Stainless Steel at Various Strains in Metallurgical Applications of Shock-Wave and High-StrainRate Phenomena, L. E. Murr, K. P. Staudhammer, and M. A. Meyers, eds., Ch. 27, Marcel Dekker, Inc., New York, 1986, p. 525

5. K. P. Staudhammer and K. A. Johnson, "Technique for Mbar Controlled Strain Experiments" in International Symposium on Intense Dynamic Loading and its Effects, Science Press, Beijing, China, June 1986, p.759.

6. K. P. Staudhammer and K. A. Johnson, in International Conference on Impact Loading and Dynamic Behavior of Materials-Impact 1987, Innformationsgesellshaft, Verlag, 1988, p. 93.

7. K. P. Staudhammer and K. A. Johnson, Ibid., p. 839.

8. K. A. Johnson, K. P. Staudhammer, N. E. Elliott and W. J. Medina, Fifth APS Topical Conference: Shock Waves in Condensed Matter, 1987, Elsevier Science Publishers B. V., The Netherlands, pp. 1988, 347-50. 